\title{
Address Terms Used by Australians: A Case Study of Melbourne
}

Dwi Mawan Karifianto ${ }^{I}$

${ }^{1}$ Corresponding author Universitas Muhammadiyah Malang, Indonesia

dwi.mawan.k@gmail.com

Received: February 24, $2020 \quad$ Accepted: June 12, $2020 \quad$ Published: January 20, 2021

\begin{abstract}
The use of address terms is an important and interesting sociolinguistic aspect to be studied. In Australian contexts, there are a number of address terms existing in daily interaction. This case study focuses on how address terms are used by Australians; specifically, 1) how often Australians use the address terms mate, babe, dude, love, buddy, darling, sweetie, and honey/hon in their everyday communication, 2) to whom they mostly use the terms towards, and 3) who is more likely to use the terms between male and female. In this study, the main data collection is survey, with the questionnaires distributed to local Australians around the area of Monash University, Melbourne. The findings suggest that from the eight address terms studied, the most frequently used one in daily interaction is mate, followed by love and dude. Next, those address terms are found to be used for various specific people depending on the closeness of relationships to the speaker. In addition, some terms are usable to address both sexes, while some can be used for certain sex only. Finally, for the speaker of those address terms, mate, buddy, and dude are more popular to use among male participants, while darling, sweetie, honey, babe, and love are more popular among female speakers. The findings in this sociolinguistic study confirm the use of address terms link to feelings and solidarity as suggested by the theory.
\end{abstract}

Keywords: Address Terms; Australia; Sociolinguistics

To cite this article: Karifianto, D. (2021). Address terms used by Australians: A case study of Melbourne. SALEE: Study of Applied Linguistics and English Education, 2(01). https://doi.org/10.35961/salee.v2i01.97

DOI: $10.35961 /$ salee.v2i01.97 


\section{Introduction}

The use of address terms is undoubtedly important in daily interactions. Philipsen and Huspek (1985) argue that personal address is a sociolinguistic subject which systematically governs language behavior on how someone will be addressed. In addition, Qin (2008) states that there are some features which play important roles in selecting appropriate address terms including interpersonal relationship and factors such as whom we are talking to, and when and where circumstances. Furthermore, the use of specific terms is also influenced by other factors such as sex, age, family relationship, occupational hierarchy, transactional status, or degree of intimacy (Yang, 2010).

In Australian contexts, there are a number of address terms existing in daily interaction such as mate, buddy, dude, babe and so forth, but not all of them are popular in everyday usages. Scientifically, some scholars have conducted investigations on the use of some address terms, and two of them are Rendle-Short (2009) and Kiesling (2004). In her study, Rendle-Short focused on mate term which use has shifted significantly from traditional to current views. The traditional view, she further explained, argues that the term mate is associated mostly with male speakers because it is closely related with masculinity, working class group, and solidarity. However, at the present time the term mate is not only commonly used by males but also by females. In her preliminary sociolinguistic survey, Rendle-Short revealed that from 97 people investigated, $88.4 \%$ male speakers and $60.4 \%$ female speakers admitted to use the term mate. The increased use of this term among female speakers noticeably widespread to young group of women due to some reasons, namely because it is fun, more intimate, and friendly when using it. Moreover, this term does not specifically represent to one gender, so it can be used to address both male and female friends or to other acquaintances in the same age.

In a similar vein, Kiesling (2004) conducted an investigation towards dude term. He described that, traditionally, the term $d u d e$ was initially popular among young men to address each other as an indicator of cool solidarity, masculine solidarity, strict heterosexuality, and nonconformity. However, its current use has expanded not only to young men but also to all groups from different age, regardless of their sex differences.

In accordance with the two previous studies, this study focuses on sociolinguistics survey about address terms used by Australians. To be more specific, it is to see how often Australians use the address terms mate, babe, dude, love, buddy, darling, sweetie, and honey/hon in their everyday communication, to whom they mostly use the terms towards, and who is more likely to use the terms between male and female.

Based on the literature, the result of this sociolinguistics survey is expected to be able to confirm the following hypotheses:

a. Address terms mate, dude, and buddy are the most frequent address terms used by Australians in their daily practices

b. Address terms mate, dude, and buddy are mostly used towards close friends

c. Males use address terms mate, dude, and buddy more than females 


\section{Method}

In this case study, the data was mainly collected by surveying local Australians. Twenty participants completed the questionaire with composition of ten males and ten females, while the age ranges from twenty to sixty five (see details in Appendix 2). Within the survey, the participants were required to answer five different questions in the questionnaires which comprise some address terms in Australian contexts. The questions include how often they use the address terms in daily basis, to whom they mostly use the terms towards, and who is more likely to use the terms between male and female. It took five to seven minutes for each participant to complete the questionnaires. Every time each participant finished completing the questionnaire, some codes are put on it, containing the order and age prediction. After that, the data is analyzed descriptively using percentage to show the general trends of the terms usage.

\section{Findings and Discussion}

This section delivers the results of data analysis from the twenty completed questionnaires distributed in the area around Monash University, Melbourne. The presentation is organized orderly based on the hypothesis statements. The details are presented in the following paragraphs.

\subsection{Frequency of Address Terms Use}

Responding to the first question about how often Australians use the eight address terms stated in the questionnaires-mate, love, dude, buddy, darling, sweetie, honey/hon, and babe-, analysis of the data reveals that mate is the most frequently used term by both male and female Australians. From the questionnaires, fourteen participants out of twenty (70\%) said they use mate in their daily interaction. It is then followed by the next terms love (50\%) and dude $(40 \%)$.

Table 1 - The use of address terms in daily basis, weekly basis, monthly basis, or never

\begin{tabular}{lll}
\hline Terms & Usage & Percentage \\
\hline Mate & Daily & $70 \%$ \\
\hline Love & Daily & $50 \%$ \\
\hline Dude & Daily & $40 \%$ \\
\hline Buddy & Weekly & $40 \%$ \\
\hline Babe & Never & $40 \%$ \\
\hline Honey / Hon & Never & $50 \%$ \\
\hline Sweetie & Never & $55 \%$ \\
\hline Darling & Never & $60 \%$ \\
\hline
\end{tabular}

Furthermore, Table 1 also shows that the other five address terms are not popular among participants to be used in daily interactions. One term, which is buddy, is preferably to use weekly with $40 \%$ participants stating it. While for the rest, the participants acknowledged that they are almost never using the following terms daily, which are baby 
with $40 \%$ participants admitted never using it, honey/hon with 50\% participants never use it, darling with $60 \%$ of participants never apply it, and sweetie as the most infrequent use with $65 \%$ of participants confessing not to practice it.

\subsection{The Use of Address Terms towards Others}

In this section, the discussion about the use of address terms towards others is divided into two categories: first, based on closeness of relationship between speakers (Table 2-3), second, based on gender.

As illustrated in Table 2, the term mate keeps its position as the most popular term among Australian. This term is applied not only to call close friends as the most favorite use (75\%), but also to call acquaintances $(65 \%)$, family $(55 \%)$, and strangers $(50 \%)$. The next most used term is love which can be used to call partners (65\%), family (55\%), and close friends $(50 \%)$. And then, buddy is the next most used with $80 \%$ to call close friends and $60 \%$ to call acquaintances.

Table 2 - The use of address terms toward others

(Participants are allowed to give multiple answers)

\begin{tabular}{lll}
\hline Terms & Addressee & Percentage \\
\hline \multirow{3}{*}{ Mate } & Close Friends & $75 \%$ \\
\cline { 2 - 3 } & Acquaintances & $65 \%$ \\
\cline { 2 - 3 } & Family & $55 \%$ \\
\cline { 2 - 3 } & Strangers & $50 \%$ \\
\hline \multirow{2}{*}{ Love } & Partners & $65 \%$ \\
\cline { 2 - 3 } & Family & $55 \%$ \\
\cline { 2 - 3 } & Close Friends & $50 \%$ \\
\hline \multirow{2}{*}{ Buddy } & Close Friends & $80 \%$ \\
\cline { 2 - 3 } & Acquaintances & $60 \%$ \\
\hline Dude & Close Friends & $80 \%$ \\
\hline Babe & Partners & $70 \%$ \\
\hline Darling & Partners & $65 \%$ \\
\hline Honey/ Hon & Partners & $65 \%$ \\
\hline Sweetie & Partners & $60 \%$ \\
\hline
\end{tabular}

For the last five address terms, they are more likely to use to one addressee only, as $d u d e$ which is used mostly to call close friends (80\%), babe to partners (70\%), darling to partners $(65 \%)$, honey/hon to partners (65\%), and sweetie to call partners, too $(60 \%)$. 
Table 3 - Variant of address terms to call friends, partners, and family members

\begin{tabular}{|l|l|l|l|}
\hline Sex & To call friends & To call partners & To call family members \\
\hline Male & $\begin{array}{l}\text { man, pal, cobber, cunt, } \\
\text { bro }\end{array}$ & dear, dearest, boo, baby & Mother, bro, sis, baby \\
\hline Female & $\begin{array}{l}\text { guys, my love, my guy, } \\
\text { my dear, bro, loser, bud }\end{array}$ & $\begin{array}{l}\text { bro, my dear, sugar } \\
\text { plum, sweetheart, BB }\end{array}$ & $\begin{array}{l}\text { Mom, Dad, bub, a pet name } \\
\text { (bear), cus, pumpkin, sis, } \\
\text { gorgeous, cutie }\end{array}$ \\
\hline
\end{tabular}

Apart from the address terms that have been provided, there are some other terms mentioned by the participants during filling out the questionnaires (Table 3), especially when they are required to mention some words to call friends, partners, and family members. The male participants wrote some terms such as man, pal, cobber, cunt, and bro when they call their friends, while the female participants wrote guys, my love, my guy, my dear, bro, loser, and bud to call friends.

On the other hand, the male participants use dear, dearest, boo, and baby to call their partners, while female participants prefer to use bro, my dear, sugar plum, sweetheart, baby, and $B B$ to address partners.

Finally, to call family members, the male participants apply bro, brother, mother, baby, and sis, whereas the female participants apply mom, dad, bub, a pet name (bear), cuz, pumpkin, sis, gorgeous, and cutie to address their family members.

In general, there is no significant difference between the terms mentioned by male and female speakers in calling friends, partners, and family members. Even, some of them are almost similar and ordinarily found in daily conversation. But, the concern here goes to the use of cunt and loser addressing to friends. These terms surely cannot be applied to all interlocutors. It needs high level of intimacy between the speakers to use it. As said by Wood and Kroger (1991), the use of address terms in communicative act and also the tone getting along with it indicates relationship power and distance between the speaker and hearer. Therefore, it will be undoubtedly offensive when we use cunt and loser to people that we do not really know well.

The second focus in the discussion of the use of address terms towards others is related to gender. In responding to a statement to whom we would likely to use address terms towards males, females, or both male and females, as illustrated in Table 4, some terms can be used not only towards one particular sex, but also to both sexes; for instance, dude can be used towards males (50\%) and both (45\%), buddy for males (50\%) and both sexes $(45 \%)$, and lastly love for females $(60 \%)$ and both sexes $(40 \%)$.

For the last five terms, the participants mostly determine to use it to single sex only, e.g. mate for males (65\%), and babe, sweetie, darling, and honey preferably for females (75\%, $75 \%, 70$, and $60 \%$ ). 
Table 4 - The likeliness to use the address terms towards males, females, or both

\begin{tabular}{lll}
\hline Terms & Sex & Percentage \\
\hline \multirow{2}{*}{ Dude } & Males & $50 \%$ \\
\cline { 2 - 3 } & Both & $45 \%$ \\
\hline \multirow{2}{*}{ Buddy } & Males & $50 \%$ \\
\cline { 2 - 3 } & Both & $45 \%$ \\
\hline \multirow{2}{*}{ Love } & Female & $60 \%$ \\
\cline { 2 - 3 } & Both & $40 \%$ \\
\hline Mate & Males & $65 \%$ \\
\hline Babe & Females & $75 \%$ \\
\hline Darling & Females & $75 \%$ \\
\hline Honey/ Hon & Females & $70 \%$ \\
\hline
\end{tabular}

\subsection{The User of Address Terms}

In the last category, it deals with who mostly use the eight terms, males or females. As illustrated in Table 5, mate (80\%), buddy (75\%), and dude (75\%) are popular to use among male participants, while darling (85\%), sweetie (80\%), honey (70\%), babe (65\%), and love (60) appear to be favorite among female speakers. But, it does not mean that different sexes do not use those terms. They use them also, but the numbers are not really significance.

Table 5 - The user of address terms (males, females, both)

\begin{tabular}{lll}
\hline Terms & Sex & Percentage \\
\hline Mate & Males & $80 \%$ \\
\hline Buddy & Males & $75 \%$ \\
\hline Dude & Males & $75 \%$ \\
\hline Darling & Females & $85 \%$ \\
\hline Sweetie & Females & $80 \%$ \\
\hline Honey/ Hon & Females & $70 \%$ \\
\hline Babe & Females & $65 \%$ \\
\hline Love & Females & $60 \%$ \\
\hline
\end{tabular}

In general, the data presented orderly in table 1 to 5 indicates the same trend as what delivered by Rendle-Short and Kiesling in their studies. There is a shifting usage among people on some address terms such as mate, buddy, dude, and love. The use of those terms lately is not dominantly practiced by one sex only, but also has extended its usage towards different sexes (as seen in Table 4). The terms dude and buddy that are well-known as male terms for years, now can be used by both sexes with $45 \%$ participants acknowledge it. In vice versa, the term love which long time ago considered for female speakers usage only, now also popular among male with $40 \%$ participants saying it. 
The findings in this sociolinguistic survey strengthen the phenomena of shifting paradigms in using address terms. Language use, including the use of address terms, inevitably link to feelings and solidarity, therefore if a speaker wants to consider distance of their relationship with a listener, the choice of address terms should be taken into account (Brown \& Levinson, 1987, as cited in Alimoradian, 2014). Relating to that statement, the use of mate, dude, or other terms among Australians currently shows significant changing into more positive sense, which is, because using those terms can make them closer to their friends, either male or female, then they will use those terms as a part of strengthening their friendship and solidarity rather than just stick on male or females stances. Therefore, it will not be surprising if the use of address terms will be in similar position between male and female speakers in the future.

\section{Conclusion}

The usage of address terms in Australian context promote some shifting paradigms from mostly mono-sexual usage to mixed sexual usage. It is caused by some positive impacts promoted by the terms as a glue of friendship among people, especially young generations. As found in the survey, mate is still as the most favorite term in daily usage basis, followed by dude, love, and buddy. Other terms such as darling, sweetie, honey and babe are also exist around, but they are least frequently used in daily usage compared to the previous terms. Other than that, it is still true that males are still dominant in the use of terms mate, dude, and buddy, but the number of females using those terms also increasing steadily. The sexes issue is not anymore significant as happening in the previous generation in affecting to the use of address terms. The current generations tend to be more open to all address terms usage.

Lastly, as this sociolinguistic survey focuses on some features like the use of the terms between male and female speakers, some studies on the use of address terms still offers a wide range of factors which needs further investigation, such as age differences, social status, and so forth, and it might produce some interesting facts which are never thought of before. 


\section{References}

Alimoradian, K. (2014). 'Makes Me Feel More Aussie': Ethnic Identity and Vocative Mate in Australia. Australian Journal of Linguistics, 34(4), 599-623. doi:10.1080/07268602.2014.929083

Kiesling, S.F. (2004). Dude. American Speech, 79(3), 281-305

Philipsen, G., \& Huspek, M. (1985). A bibliography of sociolinguistic studies of personal address. Anthropological linguistics, 27(1), 94-101. Retrieved from https://www.jstor.org/stable/pdf/30027934.pdf

Qin, X. (2008). Choices in terms of address: A sociolinguistic study of Chinese and American English practices. In Proceedings of the 20th North American Conference on Chinese Linguistics (NACCL-20) (Vol. 1, pp. 409-421).

Rendle-Short, J. (2010). 'Mate' as a term of address in ordinary interaction. Journal of Pragmatics, 42(5), 1201-1218. doi:10.1016/j.pragma.2009.09.013

Wood, L.A., \& Kroger, R.O. (1991). Politeness and forms of address. Journal of language and social psychology, 10(3), 145-168. Retrieved from http://journals.sagepub.com/doi/pdf/10.1177/0261927X91103001

Yang, X. (2010). Address forms of English: rules and variations. Journal of Language Teaching and Research, 1(5), 743-745. doi:10.4304/jltr.1.5.743-745 